\title{
Photodynamic Effect of Hypericin on the Conformation and Catalytic Activity of Hemoglobin
}

\author{
Jing Zhao ${ }^{1,2}$, Wenying Meng ${ }^{2}$, Peng Miao ${ }^{2}$, Zhiguo Yu ${ }^{1}$ and Genxi $\mathrm{Li}^{1,2^{*}}$
}

1 School of Life Science and Shanghai Key Laboratory of Bio-Energy Crops, Shanghai University, Shanghai 200444, P. R. China

2 Department of Biochemistry and National Key Laboratory of Pharmaceutical Biotechnology, Nanjing University, Nanjing 210093, P. R. China

* Author to whom correspondence should be addressed; Email: genxili@nju.edu.cn

Received: 12 September 2007 / Accepted: 30 January 2008/ Published: 5 February 2008

\begin{abstract}
Hypericin, extracted from $H$. perforatum, can induce the generation of reactive oxygen species by visible light irradiation, which may consequently induce the conformational change of hemoglobin. We have not only employed UV-vis spectroscopy to observe the changes of UV-vis spectra of the protein, which reveals the conformational changes of the protein, but also employed electrochemical method to obtain its enhanced peroxidase activity. The photodynamic effect of hypericin on the conformation and catalytic activity of the protein has also been proven to be strongly dependent on the irradiation time, the hypericin concentration and the presence of oxygen. This work is beneficial not only to the fabrication of more sensitive hydrogen peroxide biosensor, but also to the guidance of the usage of this medicinal herb molecule, since the conformational change of the protein and the enhanced peroxidase can be easily obtained only by visible light irradiation on hypericin, the process of which is so common to happen.
\end{abstract}

Keywords: Hypericin, hemoglobin, hydrogen peroxide, photodynamic effect

\section{Introduction}

Study on photosensitizers has received more and more attention. However, the effect of the photosensitization on DNA, protein, cell, or even an organ should be given more attention, no matter whether the effect is harmful or helpful for the potential clinical application. Hypericin (HY, Scheme 
1) is a phenanthroperylene quinine derivative. It can be extracted from H. perforatum, a popular medicine for the treatment of depression [1-8]. It has been used as a conventional medication for the treatment of depression and wound healing for a long time [9]. Recently, more and more interest has been given to some other important pharmaceutical potentials of this species, such as antivirus activity, anti-HIV, antibacterial activity and antitumor activity [10-12]. Most of the clinic functions are proposed to be related to the phototoxicity of HY. For instance, the cytotoxic activity can be greatly enhanced after light activation [9, 13-16]. The mechanism how it works is still to be explored, however, it is proposed that after being exposed in visible light at the wavelength of 540-600nm, HY will transfer light energy to oxygen to generate reactive oxygen species (ROS), which may further induce the apoptosis of cells [17]. Some other studies report that HY preferentially accumulates in the cell membranes, especially the mitochondria membrane, which might be the target in the photodynamic therapy [18]. Both the type I and type II photodynamic reactions can take place in the photoactivation of HY, resulting in the formation of radicals, such as singlet oxygen and superoxide radical [9].

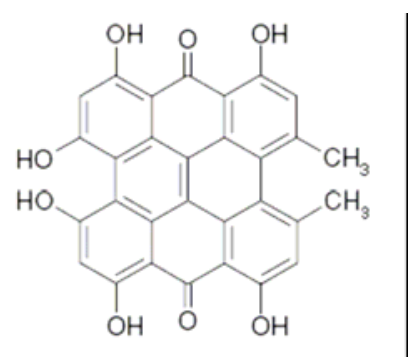

Scheme 1. Chemical structure of hypericin.

In the paper, we report our studies of the photodynamic effect of HY on the structure and function of a protein by employing UV-vis spectroscopy and electrochemical methods. Hemoglobin ( $\mathrm{Hb})$, a kind of heme protein, is used as the target protein for this work. On one hand, the structure and function of $\mathrm{Hb}$ are relatively very clear, which is easier to get to know the information of the conformational and functional changes. On the other hand, it is relatively easier to design the experimental protocols, since its electrochemistry has been somewhat largely studied in our lab $[19,20]$. Besides, we have found that the reactive molecules, such as hydroxyl radical, superoxide anions, may influence the peroxidase activity of the protein, which may be ascribed to the conformational transformation of the protein [21]. Based on the data obtained in this study, we found that visible light irradiation of the protein in the presence of HY would cause the change of its conformation. And, the peroxidase activity of the protein towards hydrogen peroxide $\left(\mathrm{H}_{2} \mathrm{O}_{2}\right)$ can be obviously enhanced. Since the structural and formational changes can take place after the treatment of the protein with visible light, the process of which is so common to occur, this study should be very interesting to lots of scientists in different research areas.

\section{Results and Discussion}

UV-vis spectroscopy is a very helpful technique to study the conformational changes of heme proteins, since the Soret band of the heme which is located at $407 \mathrm{~nm}$ can provide very useful information on the secondary structure of heme proteins [23-26]. The position of the Soret band will shift or the absorption will decrease if the structure of a heme protein is transformed. Figure 1 shows 
that the absorption of the Soret band remains almost unchanged even after $3 \mathrm{~h}$ irradiation by visible light in the absence of HY, however, the peak will decrease evidently only after 1 hour treatment if this medicinal species is in the presence. The longer the irradiation time is, the smaller the absorption peak is. Therefore, the heme moiety of the protein can be hardly influenced only by visible light. Nevertheless, irradiation treatment on $\mathrm{Hb}$ together with HY, the structure of the protein, especially the microenvironment of the heme ring, will be changed or even be badly damaged. We propose that the ROS, generated by the irradiation of HY, may react with the protein at the heme position, and change the microenvironment of the heme ring. It can be also observed from Fig.1 that the decrease of the absorption is much less significant for the case of lower HY concentration. So, the photodynamic effect of $\mathrm{HY}$ on $\mathrm{Hb}$ is not only a time dependent but also a concentration dependent process.
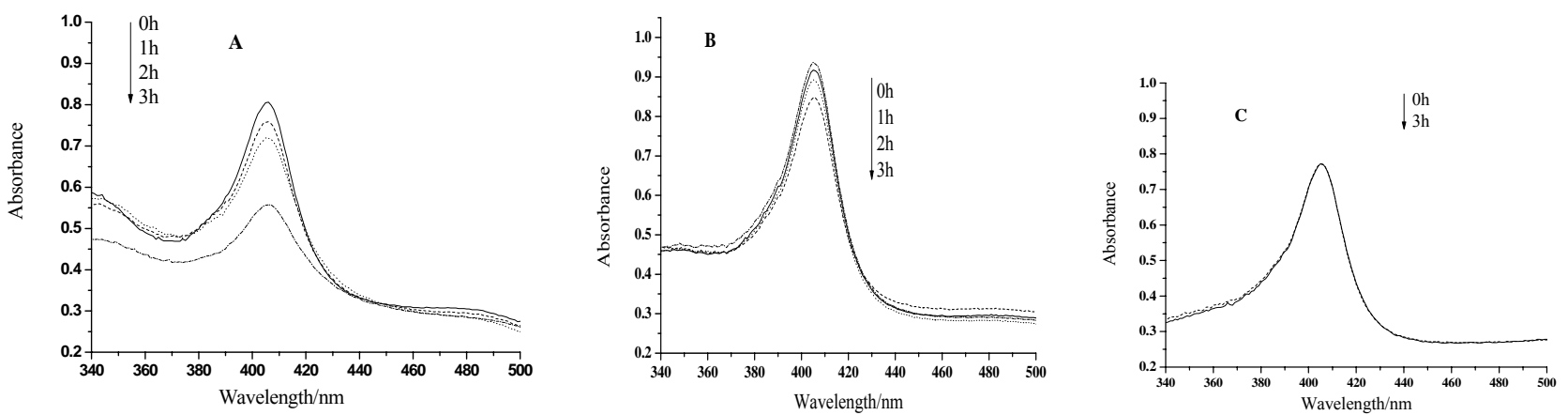

Figure 1. (A)UV-vis spectra of hemoglobin mixed with HY after visible light irradiation for $0 \mathrm{~h}, 1 \mathrm{~h}, 2 \mathrm{~h}, 3 \mathrm{~h}$, respectively. HY concentration: $5 \times 10^{-4} \mathrm{~mol} / \mathrm{L}$. Hb concentration: $3.10 \times 10^{-6} \mathrm{~mol} / \mathrm{L}$. (B) is the case for HY concentration of $2.5 \times 10^{-4} \mathrm{~mol} / \mathrm{L}$. (C) is the case for the absence of HY .

We have further employed electrochemical method to check whether the dynamic activity of HY may have any effect on the peroxidase activity of the protein. As is well known, the main physiological function of $\mathrm{Hb}$ is to carry oxygen. In the meantime, some other activities of this protein have also been revealed. Especially in recent years, the peroxidase activity of $\mathrm{Hb}$ has been largely studied, and these findings have been employed for the development of third-generation biosensors [27]. Based on our previous work of the preparation of protein-film modified electrodes and the fabrication of $\mathrm{Hb}$-based $\mathrm{H}_{2} \mathrm{O}_{2}$ biosensors with this protein [19-21], we have first prepared an $\mathrm{Hb}-\mathrm{HY}$ film modified electrode to study the catalytic activity of $\mathrm{Hb}$ towards $\mathrm{H}_{2} \mathrm{O}_{2}$. As is shown in Figure 2, the reduction peak of $\mathrm{Hb}$ will increase gradually with the addition of $\mathrm{H}_{2} \mathrm{O}_{2}$ in the test solution. Further studies reveal that a linear relationship between the increase of the reduction peak and the $\mathrm{H}_{2} \mathrm{O}_{2}$ concentration can be obtained from $1 \times 10^{-5} \mathrm{~mol} / \mathrm{L}$ to $5 \times 10^{-4} \mathrm{~mol} / \mathrm{L}$, and the linear regression equation is: $\mathrm{y}=2.15459+0.27599 \mathrm{x}, \mathrm{r}=0.999$.

In order to obtain an obvious contrast, and to more clearly show the change of the peroxidase activity of the protein, the value of the reduction peak with the addition of $1 \times 10^{-5} \mathrm{~mol} / \mathrm{L} \mathrm{H}_{2} \mathrm{O}_{2}$ is chosen as the baseline, and is set to be 0 . As is shown in Figure 3, the slope of the catalytic linearity is enhanced obviously after the irradiation of visible light on $\mathrm{Hb}$ together with $\mathrm{HY}$. So, the catalytic activity of $\mathrm{Hb}$ towards $\mathrm{H}_{2} \mathrm{O}_{2}$ has been obviously improved. And, the slope increases with the irradiation time, which suggests that a longer time treatment on the samples will result in a higher catalytic ability of the protein. Meanwhile, concentration of HY is found to be another key factor. As is shown in Figure 4, although the slopes will also increase for the case of low HY concentration, the 
changes are indistinct in the first two hours. An obvious increase can be observed only after a 3 hours irradiation. And the increase is much smaller than that for the case with high HY concentration. These experimental results obtained with electrochemical method coincide very well with the results obtained by UV-vis spectroscopy, which further reveals that the photodynamic effect of HY is not only a time-dependent, but also a concentration-dependent process.

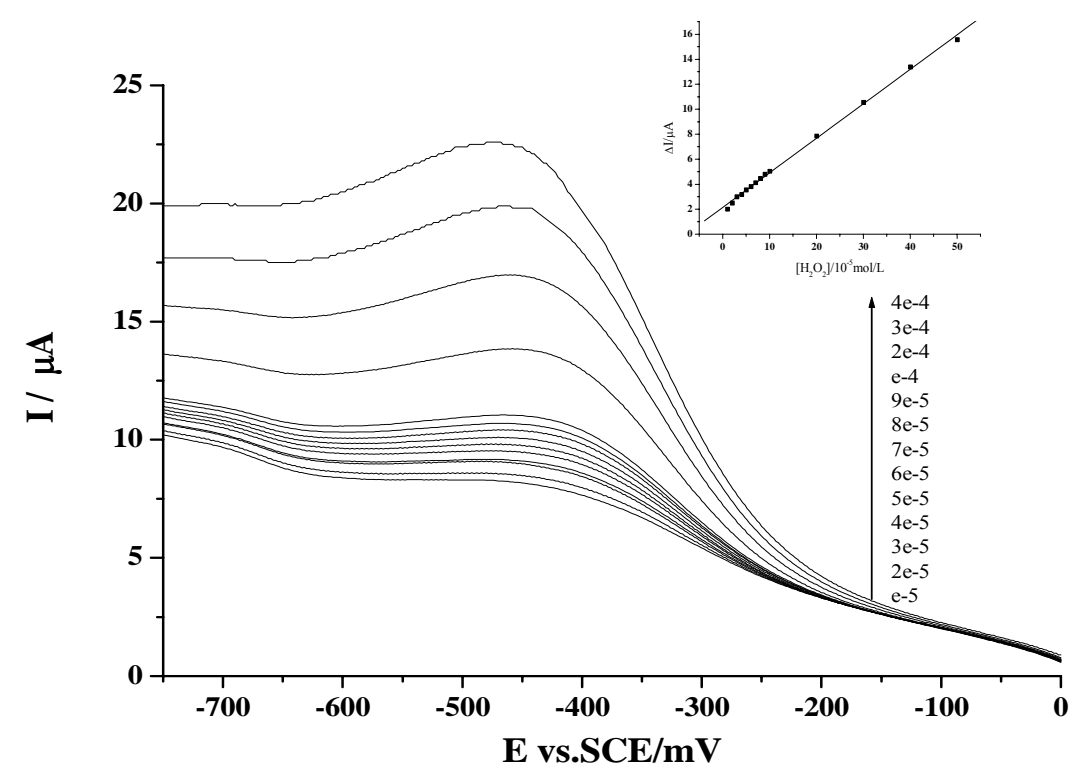

Figure 2. Voltammograms of the reduction peak obtained at a $\mathrm{Hb}-\mathrm{HY}$ modified electrode for $\mathrm{pH} 7.0$ Tris- $\mathrm{HCl}$ buffer with the additions of different concentrations of $\mathrm{H}_{2} \mathrm{O}_{2}$. Inset is plots of the reduction peak current against $\mathrm{H}_{2} \mathrm{O}_{2}$ concentration. Scan rate: $200 \mathrm{mV} \mathrm{s}^{-1}$. For the $\mathrm{Hb}-\mathrm{HY}$ modified electrode preparation, the $\mathrm{HY}$ and $\mathrm{Hb}$ concentrations are separately $1 \times 10^{-2} \mathrm{~mol} / \mathrm{L}$ and $6.20 \times 10^{-5} \mathrm{~mol} / \mathrm{L}$

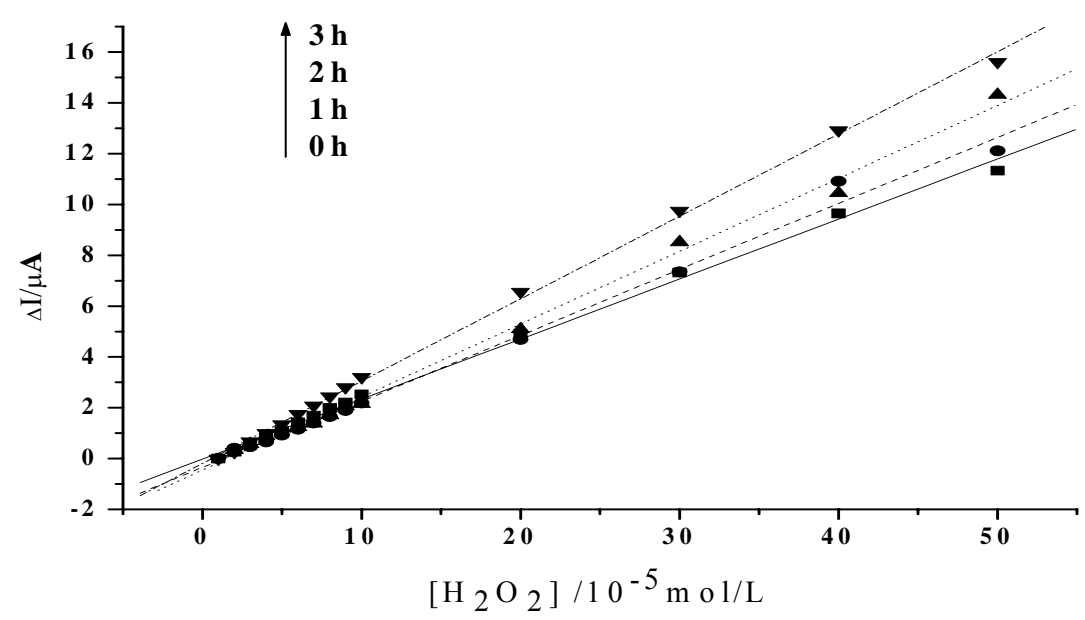

Figure 3. Linear relationship between the increase of the reduction peak current and $\mathrm{H}_{2} \mathrm{O}_{2}$ concentration after visible light irradiation of $0 \mathrm{~h}, 1 \mathrm{~h}, 2 \mathrm{~h}, 3 \mathrm{~h}$, respectively (The value of the reduction peak with $10^{-5} \mathrm{~mol} / \mathrm{L} \mathrm{H}_{2} \mathrm{O}_{2}$ is set as 0 ). Others same as in Figure 2. 


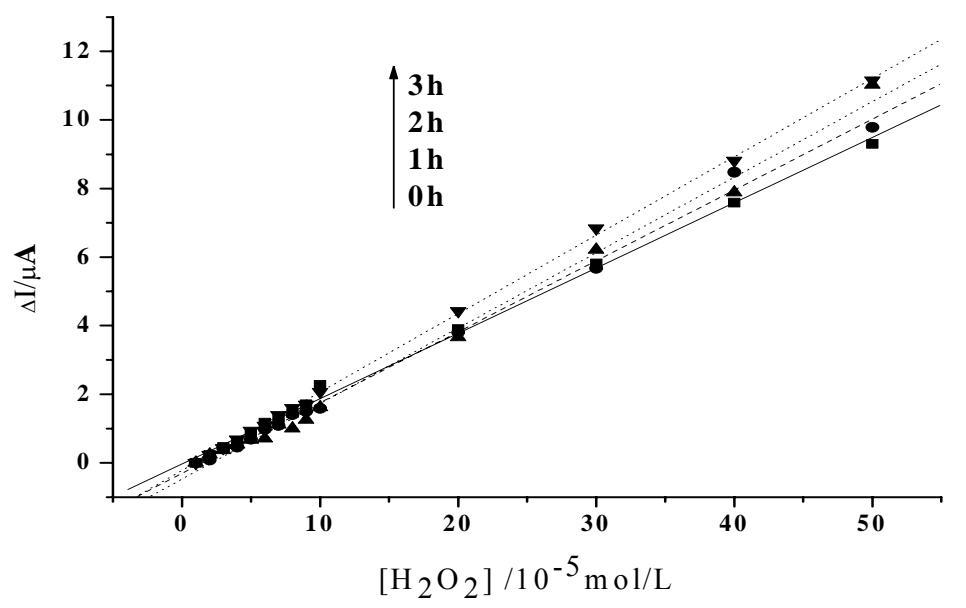

Figure 4. Linear relationship between the increase of the reduction peak current and $\mathrm{H}_{2} \mathrm{O}_{2}$ concentration after visible light irradiation of $0 \mathrm{~h}, 1 \mathrm{~h}, 2 \mathrm{~h}, 3 \mathrm{~h}$, respectively. HY concentration: $5 \times 10^{-3} \mathrm{~mol} / \mathrm{L}$. Others same as in Figure 3 .

From our further studies, this effect has also been known to be an oxygen-dependent process, although $\mathrm{O}_{2}$ is not required for the antivirus activity of HY [28]. As is shown in Fig.5, if the samples are prepared and irradiated in an anaerobic situation, the catalytic slope will keep unchanged even if a $3 \mathrm{~h}$ treatment has been made. This is reasonable, since $\mathrm{O}_{2}$ is required in a photodynamic process to generate ROS, which is crucial in photoactivating HY. So, no influence of this medicinal species on the peroxidase activity of $\mathrm{Hb}$ can be obtained without $\mathrm{O}_{2}$ being involved. These results have also confirmed that the phtosensitization of HY would be achieved only in the presence of oxygen. After absorbing the light energy, HY will be transformed to be an excited state, which may further transfer the energy to oxygen directly or indirectly, both of which induce the formation of the ROS, especially the singlet oxygen. ROS then react with $\mathrm{Hb}$, which may induce the change of the microenvironment of the heme position. As a result, the catalytic ability of the protein towards $\mathrm{H}_{2} \mathrm{O}_{2}$ is enhanced.

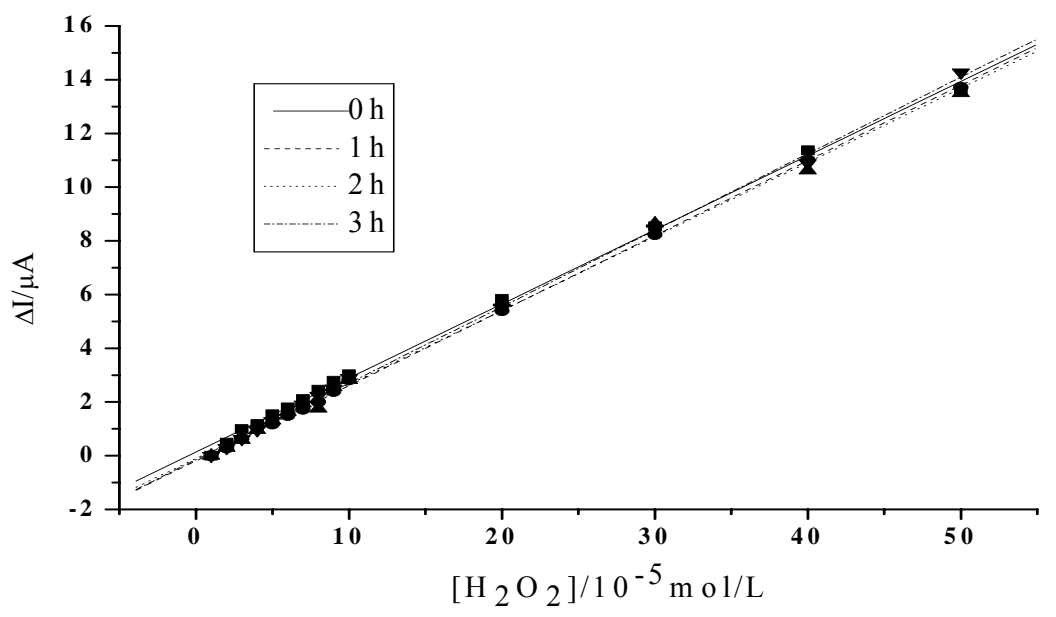

Figure 5. Linear relationship between the increase of the reduction peak current and $\mathrm{H}_{2} \mathrm{O}_{2}$ concentration after visible light irradiation of $0 \mathrm{~h}, 1 \mathrm{~h}, 2 \mathrm{~h}, 3 \mathrm{~h}$, respectively in an anaerobic condition. Others same as in Figure 3. 
In summary, with UV-vis spectroscopic and electrochemical techniques, we have found that irradiation on the mixture of $\mathrm{Hb}$ and $\mathrm{HY}$ by the very common visible light can activate $\mathrm{HY}$ to generate ROS, which will make the change of the structure of $\mathrm{Hb}$ and enhance the catalytic activity of the protein towards the $\mathrm{H}_{2} \mathrm{O}_{2}$ reduction. This process depends not only on the irradiation time but also on the concentration of $\mathrm{HY}$. Meanwhile, $\mathrm{O}_{2}$, which is required for the generation of ROS, is also found to be a vital element in the photoactive effect. This work has not only confirmed the photosensitization of $\mathrm{HY}$ and revealed the enhanced peroxidase activity of $\mathrm{Hb}$, but also be helpful to the development of more sensitive $\mathrm{H}_{2} \mathrm{O}_{2}$ biosensor and the usage of this medicinal herb molecule.

\section{Experimental Section}

\subsection{Reagents}

HY ( $99 \%)$ was purchased from Shanghai Healthjoy Chemical Co. Ltd. Stock solutions were prepared by dissolving known amounts of HY in $1 \mathrm{~mL}$ of dimethyl sulphoxide (DMSO). Hb from bovin blood was purchased from Sigma and used without further purification. Stock solutions were prepared by dissolving known amounts of $\mathrm{Hb}$ in $1 \mathrm{~mL}$ of double-distilled water. DMSO and $\mathrm{H}_{2} \mathrm{O}_{2}$ $(30 \%$ (w/v) solution) were provided from Shanghai Jinshan Tingxin Chemical Reagent Co. and Nanjing Chemical Reagent Co., respectively. Other chemicals were of analytical grade. Doubledistilled water, which was purified with a Milli-Q purification system (Branstead, Boston, MA, U.S.A.) to a specific resistance of $>18 \mathrm{M} \Omega \mathrm{cm}$, was used in all the experiments, and all the solutions were stored in the refrigerator at $4{ }^{\circ} \mathrm{C}$.

\subsection{Preparation of UV-vis spectroscopic samples and light treatment}

Sample I preparation: $1 \mu \mathrm{L}$ HY solution $(0.1 \mathrm{~mol} / \mathrm{L}), 5 \mu \mathrm{L} \mathrm{Hb}(8 \mathrm{mg} / \mathrm{ml}, \mathrm{pH} 7.0)$ and $4 \mu \mathrm{L}$ Tris- $\mathrm{HCl}$ buffer ( $\mathrm{pH}$ 7.0) were mixed in a microcentrifuge tube.

Sample II preparation: $0.5 \mu \mathrm{L}$ HY solution $(0.1 \mathrm{~mol} / \mathrm{L}), 5 \mu \mathrm{L} \mathrm{Hb}(8 \mathrm{mg} / \mathrm{ml}, \mathrm{pH} 7.0)$ and $4 \mu \mathrm{L}$ Tris- $\mathrm{HCl}$ buffer ( $\mathrm{pH}$ 7.0) were mixed in a microcentrifuge tube.

Sample III preparation: $1 \mu \mathrm{L}$ HY solution $(0.1 \mathrm{~mol} / \mathrm{L}), 5 \mu \mathrm{L} \mathrm{Hb}(8 \mathrm{mg} / \mathrm{ml}, \mathrm{pH} 7.0)$ and $4 \mu \mathrm{L}$ Tris- $\mathrm{HCl}$ buffer ( $\mathrm{pH}$ 7.0) were mixed in a microcentrifuge tube. This sample was thoroughly deoxygenated by blowing high-purity nitrogen for at least $1 \mathrm{~min}$, and then sealed by parafilm.

The samples were exposed in the visible light emitted by a $200 \mathrm{~W}$ filament lamp, which was filtered by an orange filer to get a wide band illumination above $580 \mathrm{~nm}$, for $1 \mathrm{~h}, 2 \mathrm{~h}, 3 \mathrm{~h}$, respectively, at a distance of $20 \mathrm{~cm}$.

\subsection{Spectrocopic measurements}

UV-vis spectroscopy was performed using a UV-2550 spectrophotometer (Shimadzu, Japan). After the treatment with visible light irradiation, the samples were then twentyfold diluted and analyzed immediately with the spectrophotometer. The blank was a $0.1 \mathrm{M}$ tris- $\mathrm{HCl}$ solution $(\mathrm{pH} 7.0)$. 


\subsection{Preparation of the modified electrode}

The substrate pyrolytic graphite $(\mathrm{PG})$ electrode $\left(\mathrm{A}=6.28 \mathrm{~mm}^{2}\right)$ was prepared by inserting a PG rod in a glass tube and fixing it with epoxy resin. Electrical contact was made by attaching a copper wire to the rod with the help of Wood's alloy (a fusible bismuth-based alloy). Before the modification of the substrate electrode with HY and the protein, the substrate PG electrode was first polished using rough and fine sand papers. Its surface was then polished to mirror smoothness with alumina (particle size of approx. $0.05 \mu \mathrm{m}$ )/water slurry on silk. Finally, the electrode was thoroughly washed by ultrasonicating in both double-distilled water and ethanol for approx. $5 \mathrm{~min} .10 \mu \mathrm{L}$ of $\mathrm{HY}$ and $\mathrm{Hb}$ mixture with their concentration being $1 \times 10^{-2} \mathrm{~mol} / \mathrm{L}$ and $6.2 \times 10^{-5} \mathrm{~mol} / \mathrm{L}$, respectively, was mixed with $10 \mu \mathrm{L}$ DMSO (20\%) and then spread evenly on the surface of the substrate PG electrode. The HY and Hb mixture had been previously treated with visible light irradiation before its immobilization onto PG electrode surface. The modified electrode was dried overnight at room temperature in the dark. After that, this electrode was thoroughly rinsed with double-distilled water and could be ready for use.

\subsection{Electrochemical Apparatus}

Cyclic voltammetry (CV) was performed with a PARC 263A Potentiostat/Galvanostat (EG\&G; Princeton, NJ, USA), using a three-electrode configuration at $25 \pm 0.5{ }^{\circ} \mathrm{C}$. The reference electrode was a saturated calomel electrode (SCE) and the counter electrode was a platinum electrode. Potentials are reported with respect to SCE unless specially stated. All the test solutions were thoroughly deoxygenated by bubbling high-purity nitrogen through the solution for at least $10 \mathrm{~min}$. A stream of nitrogen was blown gently across the surface of the solution in order to maintain the solution anaerobic throughout the experiments.

\section{Acknowledgements}

This work is supported by the National Natural Science Foundation of China (Grant No. 90406005, 20575028), the Program for New Century Excellent Talents in University, the Chinese Ministry of Education (NCET-04-0452) and the Shanghai Municipal Education Commission (No.06AZ051).

\section{References and Notes}

1. Pace, N.; MacKinney, G. Hypericin. The Photodynamic Pigment from St. John's Wort. J. Am. Chem. Soc. 1941, 63 , 2570-2574.

2. Bilia, A. R.; Gallori, S.; Vincieri, F. F. St. John's Wort and depression: efficacy, safety and tolerability - an update. Life Sci. 2002, 70, 3077-3096.

3. Greeson, J. M.; Sanford, B.; Monti, D. A. St. John's Wort (Hypericum perforatum):a review of the current pharmacological, toxicological, and clinical literaturel. Psychopharmacology (Berl) 2001, 153, 402-414.

4. Barnes, J.; Anderson, L. A.; Phillipson, J. D. St John's Wort (Hypericum perforatum L.): a review of its chemistry, pharmacology and clinical properties. J. Pharm. Pharmacol. 2001, 53, 583-600.

5. Miskovsky, P.; Sureau, F.; Chinsky, L.; Turpin, P.Y. Subcellular distribution of hypericin in human cancer cells. Photochem. Photobiol. 1995, 62, 546-549. 
6. Kamuhabwa, A. R.; Augustijns, P.; De Witte, P. A. In vitro transport and uptake of protohypericin and hypericin in the Caco-2 model. Int. J. Pharm. 1999, 188, 81-86.

7. Chen, B.; de Witte, P. A. Photodynamic therapy efficacy and tissue distribution of hypericin in a mouse P388 lymphoma tumor model. Cancer Lett. 2000, 150, 111-117.

8. Andreoni, A.; Colasanti, A.; Colasanti, P.; Mastrocinque, M.; Riccio, P.; Roberti, G. Laser photosensitization of cells by hypericin. Photochem. Photobiol. 1994, 59, 529-533.

9. Guedes, R. C.; Eriksson, L. A. Theoretical study of hypericin. J. Photochem. Photobiol. A-Chem. 2005, 172, 293-299.

10. Miskovsky, P. A New Antiviral and Antitumor Photosensitizer: Mechanism of Action and Interaction with Biological Macromolecules. Curr. Drug Targets 2002, 3, 55-84.

11. Wang, S.; Liang, J.; Yang, L.; Cui, Y.; Shang, R.; Luo, Y. Studies on the inhibitory effect of hypericin on foot-and-mouth virus in vitro. Chin. J. Vet. med. 2006, 42, 6-9.

12. Ulicny, J.; Laaksonen, A. Hypericin, an intriguing internally heterogenous molecule, forms a covalent intramolecular hydrogen bond. Chem. Phys. Lett. 2000, 319, 396-402.

13. Hadjur, C.; Richard, M. J.; Parat, M. O.; Jardon, P.; Favier, A. Photodynamic effects of hypericin on lipid peroxidation and antioxidant status in melanoma cells. Photochem. Photobiol. 1996, 64, 375-381.

14. Theodossiou, T.; Spiro, M. D.; Jacobson, J.; Hothersall, J. S.; Mac-Robert, A. J. Evidence for intracellular aggregation of hypericin and the impact on its photocytotoxicity in PAM 212 murine keratinocytes. Photochem. Photobiol. 2004, 80, 438-443.

15. Thomas, C.; MacGill, R. S.; Miller, G. C.; Pardini, R. S. Photoactivation of hypericin generates singlet oxygen in mitochondria and inhibits succinoxidase. Photochem. Photobiol. 1992, 55, 47-53.

16. Thomas, C.; Pardini, R. S. Oxygen dependence of hypericininduced phototoxicity to EMT6 mouse mammary carcinoma cells. Photochem. Photobiol. 1992, 55, 831-837.

17. Lu, W. D.; Atkins, W.M. A Novel Antioxidant Role for Ligandin Behavior of Glutathione STransferases: Attenuation of the Photodynamic Effects of Hypericin. Biochemistry 2004, 43, 12761-12769.

18. Theodossiou, T. A.; Noronha-Dutra, A.; Hothersall, J. S. Mitochondria are a primary target of hypericin phototoxicity:Synergy of intracellular calcium mobilisation in cell killing. Int. J. Biochem. Cell B. 2006, 38, 1946-1956.

19. Wang, H.; Guan, R.; Fan, C.; Zhu, D.; Li, G. A hydrogen peroxide biosensor based on the bioelectrocatalysis of hemoglobin incorporated in a kieselgubr film. Sensors and Actuators B 2002 , 84, 214-218.

20. Fan, C.; Gao, Q.; Zhu, D.; Wagner, G.; Li, G. An unmediated hydrogen peroxide biosensor based on hemoglobin incorporated in a montmorillonite membrane. Analyst 2001, 126, 1086-1089.

21. Zhou, H.; Gan, X.; Wang, J.; Zhu, X.; Li, G. Hemoglobin-Based Hydrogen Peroxide Biosensor Tuned by the Photovoltaic Effect of Nano Titanium Dioxide. Anal. Chem. 2005, 77, 6102-6104.

22. Geoge, P.; Hanania, G. A spectrophotometric study of ionizations in methaemoglobin. Biochem. J. 1953, 55, 236-243.

23. Sakai, H.; Masada, Y.; Onuma, H.; Takeoka, S.; Tsuchida, E. Reduction of Methemoglobin via Electron Transfer from Photoreduced Flavin: Restoration of O2-Binding of Concentrated Hemoglobin Solution Coencapsulated in Phospholipid Vesicles. Bioconjugate Chem. 2004, 15, 1037-1045. 
24. Sakai, H.; Onuma, H.; Umeyama, M.; Takeoka, S.; Tsuchida, E. Photoreduction of Methemoglobin by Irradiation in the Near-Ultraviolet Region. Biochemistry 2000, 39, 14595-14602.

25. Teramura, Y.; Kanazawa, H.; Sakai, H.; Takeoka, S.; Tsuchida, E. Prolonged Oxygen-Carrying Ability of Hemoglobin Vesicles by Coencapsulation of Catalase in Vivo. Bioconjugate Chem. 2003, 14, 1171-1176.

26. Brown, W. D.; Snyder, H. E. Nonenzymatic reduction and oxidation of myoglobin and hemoglobin by nicotinamide adenine dinucleotides and flavins. J. Boil. Chem. 1969, 244, 6702-6706.

27. Li, G. In Encyclopedia of Sensor; Grimes, C. A., Dickey, E. C., Pishko, M. V., Eds.; American Scientific Publishers: Valencia, CA, 2006; p. 301-313

28. Sanchez-Cortes, S.; Miskovsky, P.; Jancura, D.; Bertoluzza, A. Specific Interactions of Antiretroviraly Active Drug Hypericin with DNA As Studied by Surface-Enhanced Resonance Raman Spectroscopy. J. Phys. Chem. 1996, 100, 1938-1944.

(C) 2008 by MDPI (http://www.mdpi.org). Reproduction is permitted for noncommercial purposes. 